\title{
PREDICTIVE ON-OFF COST MINIMIZING CONTROL OF A MUNICIPAL WASTE WATER TREATMENT PLANT
}

\author{
U. Schmitz, R. Haber, F. Lang
}

Dept. of Plant Design and Chemical Process Engineering, Lab. of Process Control, University of Applied Science Cologne, D-50679 Köln, Betzdorfer Str. 2, Germany fax: +49-221-8275-2201,e-mail:\{ ulrich.schmitz, robert.haber\}@fh-koeln.de\}

\begin{abstract}
With intermittently operated municipal waste water plants the aeration switching sequence should be optimized under the constraints that the solved nitrogen concentration in effluent has to be kept within its environmental limits. This is a highly nonlinear control problem because of the nonlinear biological process model ASM1 (Activated Sludge Model 1), the on-off state of the manipulated sequence and the concentration constraints. The constrained optimization was transformed to the unconstrained optimization of the predictive on-off control, as the violations of the constraints were converted to their economical costs. Furthermore, the cost of the aeration was considered in the cost function. Copyright (C) 2005 IFAC
\end{abstract}

Keywords: predictive control, municipal waste water treatment, nonlinear models.

\section{INTRODUCTION}

A municipal sewage plant is usually a WWTP (Waste Water Treatment Process) with an intermittently operated nitrification/denitrification

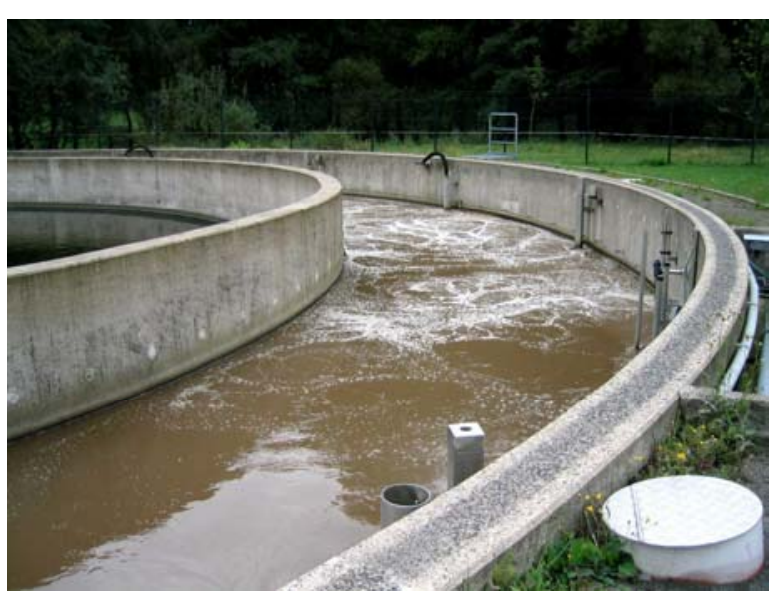

Fig. 1. A intermittently operated waste water treatment plant in Germany process. For this class of processes an on-off controller is used to switch the aeration on or off or to set the reference value for a conventional PIcontroller which controls the concentration of the solved oxygen in the biological reactor.

In most cases the on-off controller works between two limit values, an upper and a lower boundary or switching point. These boundary values are generally set empirically in such a way that the values of the effluent of the plant are kept within their legal limit values.

One possible way for the optimization based on the whole ASM1 model (Henze et. al. 1987) is shown by Fikar, Chachuat and Latifi (2002) and Latifi (2003). They show in an example of a small-sized alternating treatment plant the possibility to save costs by reducing the on-time of an on-off-controller, which controls the aeration. Therefore, they fixed the number of cycles and limited the minimum of the on- and off-time to $15 \mathrm{~min}$ and the maximum to 120 $\mathrm{min}$. Another method for optimization is exemplified on a simplified model, which is based also on the 
ASM1 is shown in Lukasse, Keesman and Straten (1999). With this model the number of the parameters has been reduced and the unknown parameters were estimated recursively. Besides a cost function based on the one-step-ahead predicted concentrations was optimized.. In Kim et al. (2000) also a reduced model was used. In this case the fraction of the aeration time and the total cycle time has been optimized. Admittedly they also have demonstrated their optimization on a small-sized alternating sludge process in bench-scale unit.

In this paper a new optimizing algorithm is presented in order to find the best switching sequence using predictive model based simulations, and in order to directly search for the control which causes the least cost for the operator of the plant. This means that the cost factor of the cost function really has the unit of a currency, e.g. Euro $(€)$.

\section{THE INTERMITTENTLY OPERATED WASTE WATER TREATMENT PLANT}

During the nitrification phase of the process a waste water basin is filled with oxygen, thus the basin is operated aerobic and ammonium is converted to nitrate. The denitrification phase is operated anaerobic. During the dentirification the $\mathrm{NO}_{3}$ which is built during the nitrification, is converted to $\mathrm{N}_{2}$.

In smaller waste water treatment plants the nitrification and denitrification phases are operated alternatively, thus the two stages of the nitrogen elimination process are separated chronologically and not spacially. This is realised by operating the activated sludge basin once aerobe and then anaerobe in turn. The switching between the aerobe and the anaerobe operation can be realised by a time schedule or by on-off control of the $\mathrm{NO}_{3}$ concentration in the basin. Fig. 2 shows the scheme of such a nitrification/denitrification process operated intermittently.

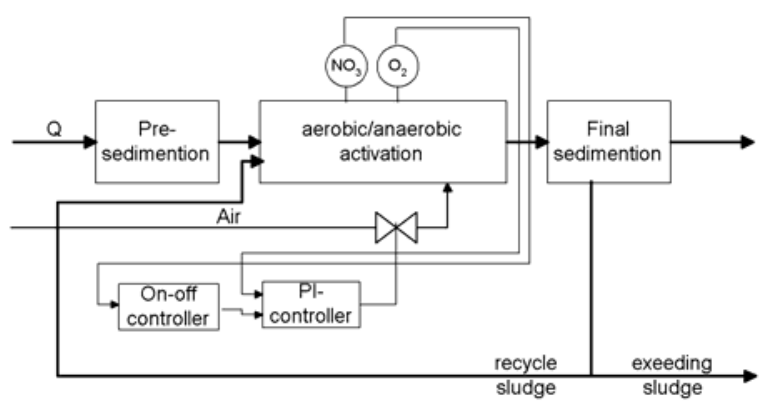

Fig. 2. Nitrification/denitrification part of the waste water treatment process controlled by a cascade structure of an on-off and a PI controller

The oxygen is discharged into the basin by an aeration fan which is controlled by a conventional PI controller. The on-off controller has to keep the concentration of NOx by setting the reference value of the PI controller.
For the control of this process first a conventional on-off controller was used. The switching points for the controller were set to $1 \mathrm{mg} / 1 \mathrm{NO}_{3}$ for the lower switching point and $4 \mathrm{mg} / 1 \mathrm{NO}_{3}$ for the upper point. The interesting point of view is that legal limits exist for the total nitrogen concentration and for the solved $\mathrm{NH}_{4}$ but not for $\mathrm{NO}_{3}$ which is used for the onoff controller in this case.

For the simulation of the waste water treatment process the program package SIMBA of the Institute for Automation and Communication (IFAK) in Magdeburg, Germany, was used (Alex, To and Hartwig, 2002; Jumar and Alex, 2002). This program package is an add-on library for MATLAB/SIMULINK for a waste water treatment process.

\section{THE COST-OPTIMIZATION OF THE WASTE WATER TREATMENT PLANT}

The traditional idea of controlling an intermittently operated WWTP is to control the concentration of the $\mathrm{NO}_{3}$ by using an on-off controller which is set to empirically discovered switching points, in order to keep the effluent concentrations in the legal limits. In this work the approach is not to achieve a better control of the $\mathrm{NO}_{3}$-concentration but to achieve a more cost efficient control of the plant.

First we have to take a look at the actions which can produce costs and which really produce costs while the plant operates. The actions which can produce costs should be prevented completely and the actions which really produce costs should be minimized as well as possible.

The actions which can produce costs are:

- any violation of the legal limits of the total nitrogen concentration.

- any violation of the legal limits of the $\mathrm{NH}_{4}$.

The actions which always produce costs are:

- the duration of aeration, because of the energyconsumption of the fan

- the number of switching on and switching off the aeration because each alternation of load rises the abrasion of the fan and therefore increases the costs.

With this background the cost function to be optimized is as follows:

$$
J=J_{\Sigma N}+J_{N H 4}+J_{O n-O f f}+J_{O n}
$$

with

$$
J_{\Sigma N}=\lambda_{\Sigma N} \sum_{t_{\text {start }}}^{t_{\text {end }}}\left\{\begin{array}{lll}
0 & \text { for } & \left(c_{N O 3, i}+c_{N H 4, i}\right) \leq L_{\Sigma N} \\
1 & \text { for } & \left(c_{N O 3, i}+c_{N H 4, i}\right)>L_{\Sigma N}
\end{array}\right.
$$




$$
\begin{aligned}
& J_{N H 4}=\lambda_{N H 4} \sum_{t_{\text {start }}}^{t_{\text {end }}}\left\{\begin{array}{lll}
0 & \text { for } & c_{N H 4, i} \leq L_{N H 4} \\
1 & \text { for } & c_{N H 4, i}>L_{N H 4}
\end{array}\right. \\
& J_{\text {On-Off }}=\lambda_{\text {On-Off }} \sum_{t_{\text {start }}}^{t_{\text {end }}}\left|\frac{\Delta u_{i}}{\Delta t}\right| \\
& J_{\text {On }}=\lambda_{\text {On }} \sum_{t_{\text {start }}}^{t_{\text {end }}} u_{i}
\end{aligned}
$$

with

$\lambda_{\Sigma \mathrm{N}}$ : weighting factor for limit-overshoot for the sum of all nitrogen,

$\lambda_{\mathrm{NH} 4}$ : weighting factor for limit-overshoot for $\mathrm{NH}_{4}$,

$\lambda_{\text {On-Off }}$ weighting factor for switching the aeration on or off,

$\lambda_{\text {On }}$ : weighting factor for the duration of aeration,

$\mathrm{c}_{\mathrm{NO} 3}$ : concentration of $\mathrm{NO}_{3}$ in the effluent of the basin,

$\mathrm{c}_{\mathrm{NH} 4}$ : concentration of $\mathrm{NH}_{4}$ in the effluent of the basin,

$\mathrm{u}$ : the output of the on-off controller (only the states " 0 " and " 1 " are allowed), i.e. the optimization variable, thus a vector which describes the state of the aeration in each sampling step,

$\mathrm{L}_{\Sigma \mathrm{N}}$ : the allowed limit for total nitrogen concentration in the effluent of the plant usually set to $13 \mathrm{mg}$ / in Germany,

$\mathrm{L}_{\mathrm{NH} 4}$ : the allowed limit for the concentration of $\mathrm{NH}_{4}$ in the effluent of the plant - usually set to $10 \mathrm{mg} / \mathrm{l}$ in Germany.

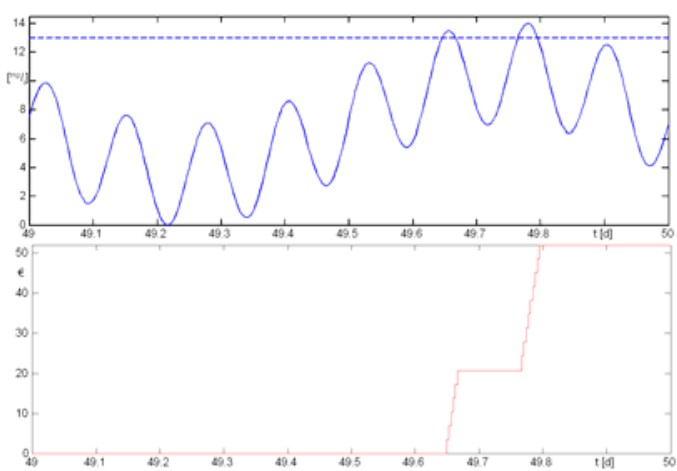

Fig. 3. Violation of the given legal limit and the corresponding cost factor scaled over one day.

The weighting factors were used to calculate the real costs of the cost function (in this case in the currency " $€$ "). In the explicit case the weighting factors were chosen to:

- $\lambda_{\Sigma \mathrm{N}}=1000,-[€ /$ day $] * \mathrm{t}_{\text {sample }}[$ day $]-$ because the administrative fine for a violation of the limit is 1000 ,-€ per day,

- $\quad \lambda_{\mathrm{NH} 4}=1000,-\left[€ /\right.$ day $*^{*} t_{\text {sample }}[$ day $]$ - because the administrative fine for a violation of the limit is $1000,-€$ per day,
- $\lambda_{\text {On-Off }}=0.25 €$ costs for the higher abrasion of the fan,

- $\lambda_{\text {On }}=0.03 € / \mathrm{min}$ costs for the operation of the aeration.

Figures 3 to 6 demonstrate the mode of functioning of the cost function. The first two terms of the cost function rise only if the given limit is violated. In Fig. 3 (and zoomed in Fig. 4) it can be seen that the cost factor rises only in those sampling steps where the legal limit was violated.

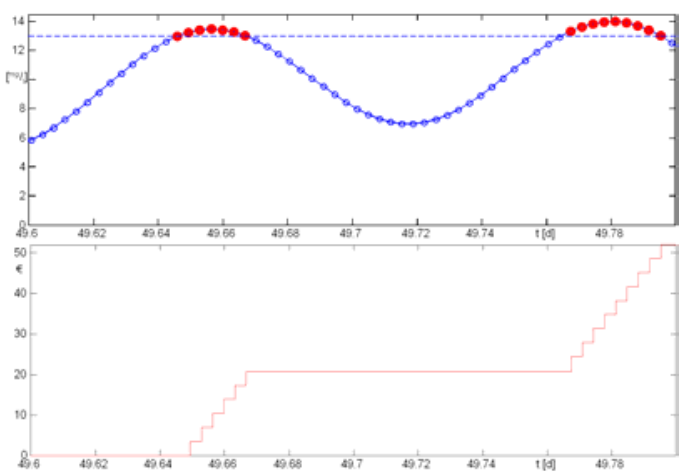

Fig. 4. Violation of the given legal limit and the corresponding cost factor scaled over 0.2 days.
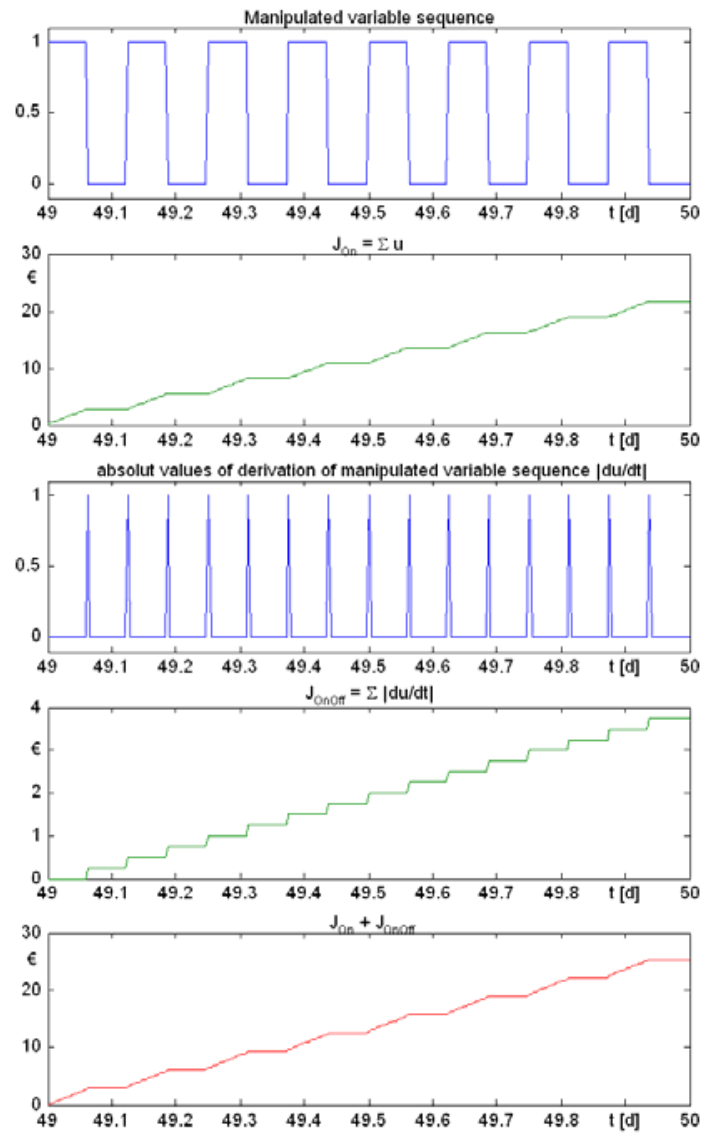

Fig. 5. Progression of the cost factors $\mathrm{J}_{\mathrm{On}}$ and $\mathrm{J}_{\text {On-Off }}$ for higher relative switching on percent (about $50 \%)$

Figures 5 and 6 present the costs which occur by switching and operating the aeration for two different manipulated variable sequences (Fig. 6 for about $50 \%$ on-time and Fig. 6 for about $25 \%$ on- 
time). It can be seen that the factor $\mathrm{J}_{\mathrm{On}}$ rises only in the points where the aeration is operating and that the factor $\mathrm{J}_{\text {On-Off }}$ rises stepwise in the points where the aeration is switched on or off.
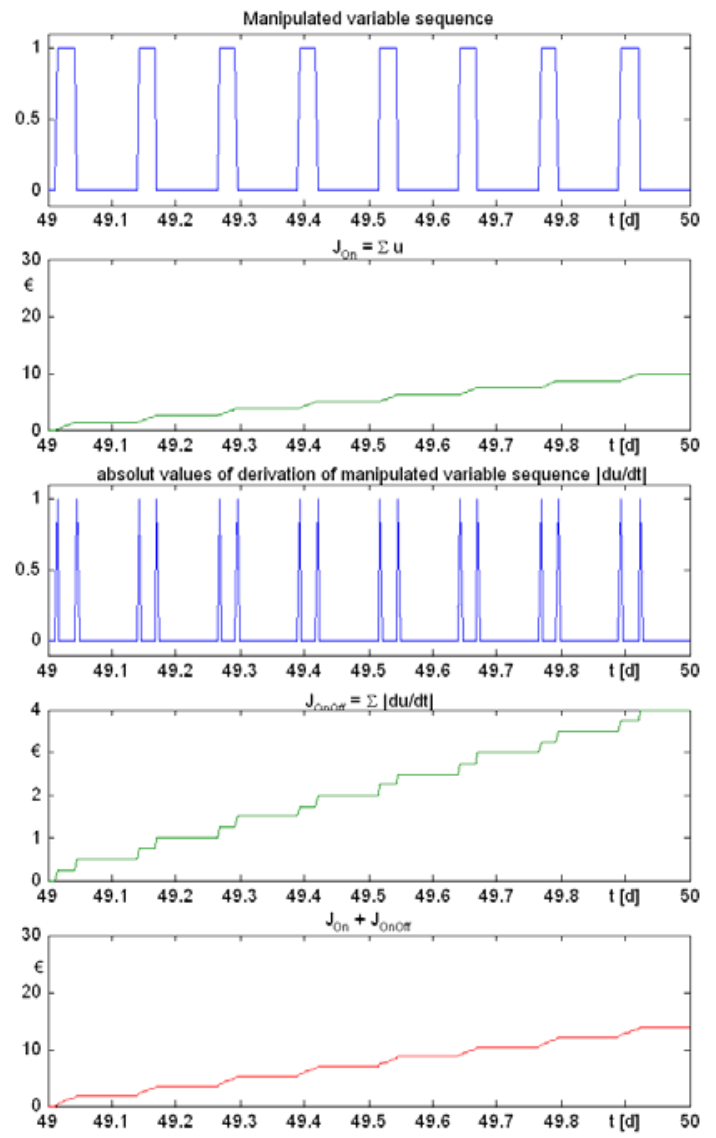

Fig. 6. Progression of the cost factors $\mathrm{J}_{\mathrm{On}}$ and $\mathrm{J}_{\mathrm{On}-\mathrm{Off}}$ for lower relative switching on percent (about $25 \%)$

The optimization of the cost function was performed online and predictive for the next 24 hours. That means the prediction and optimizing horizon were 24 hours while the sampling time was $5 \mathrm{~min}$. However, the plant was simulated by the toolbox SIMULINK/SIMBA continuously and sampled afterwards. Fig. 8 shows the minimization of the cost function by using the genetic algorithm of Sekaj (2002). The optimization was started from the conventional on-off-control as shown in Fig. 8. The corresponding cost function was the initial value in Fig. 7.

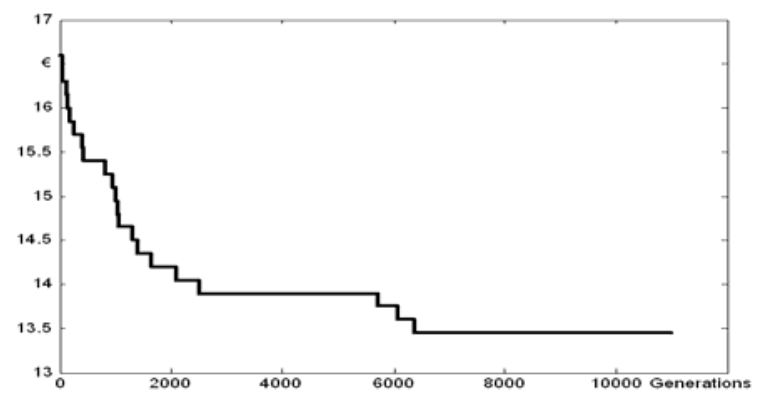

Fig. 7. Reduction of the cost function during the genetic optimization process

\section{SIMULATION AND OPTIMIZATION RESULTS}

Figures 8 and 9 show the effluent concentrations $\mathrm{NO}_{3}, \mathrm{NH}_{4}$ and the total nitrogen concentration with a conventional on-off controller for 1 and 0,2 days, respectively. Figures 10 and 11 show the same effluent concentrations with the optimized manipulated variable for 1 and 0,2 days, respectively.

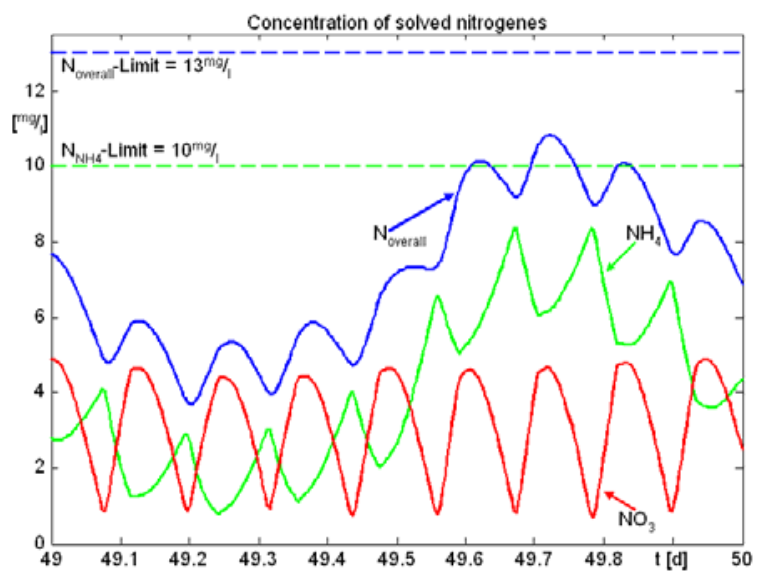

Fig. 8. Effluent concentrations with a conventional on-off controller for 1 day

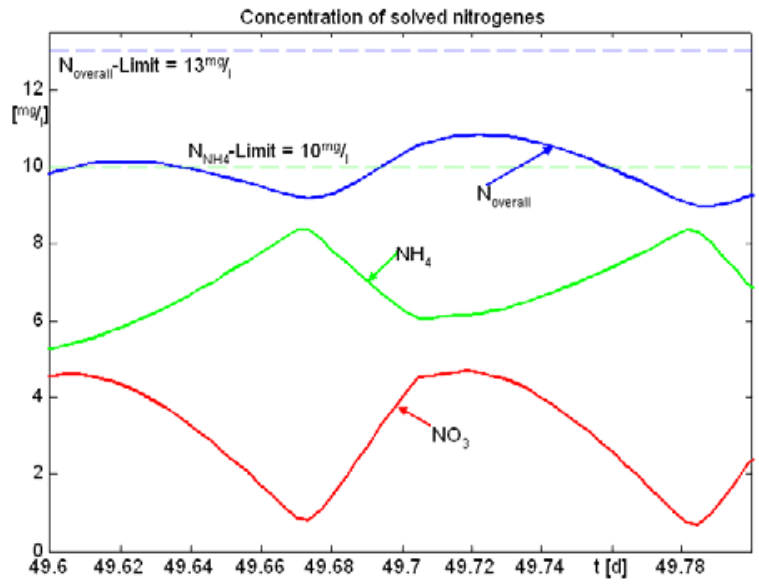

Fig. 9. Effluent concentrations with a conventional on-off controller zoomed for 0.2 day's

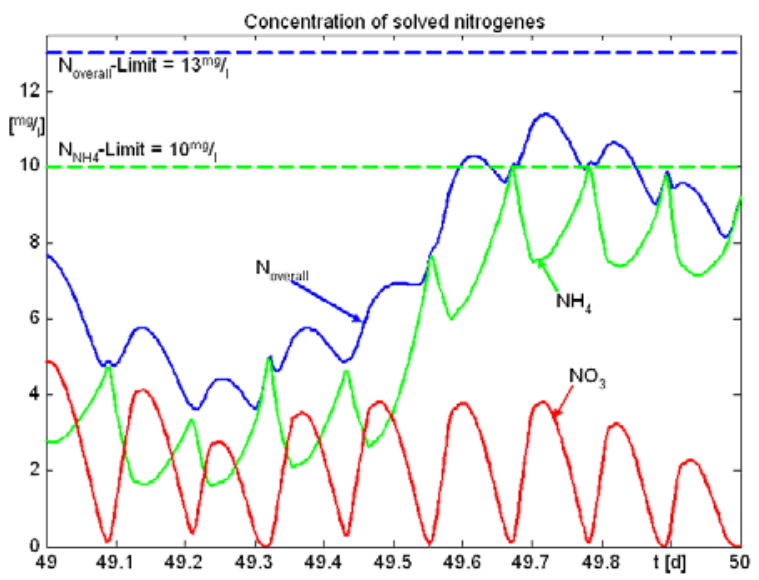

Fig. 10. Effluent concentrations with the optimized manipulated variable sequence for 1 day 


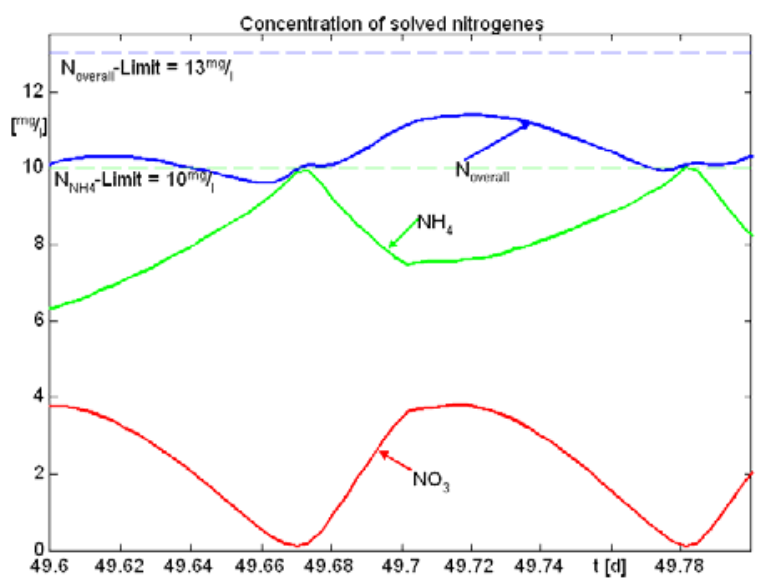

Fig. 11. Effluent concentrations with the optimized manipulated variable sequence zoomed for 0.2 day's

Figures 12 and 13 show the same concentrations in the influent of the plant for the conventional and the predictive on-off controller. (The curves slightly differ from the real waste water influent-values, because the influent measurements are placed directly before the biological reactor of the plant and the inflow of the biological reactor also includes the return sludge.)

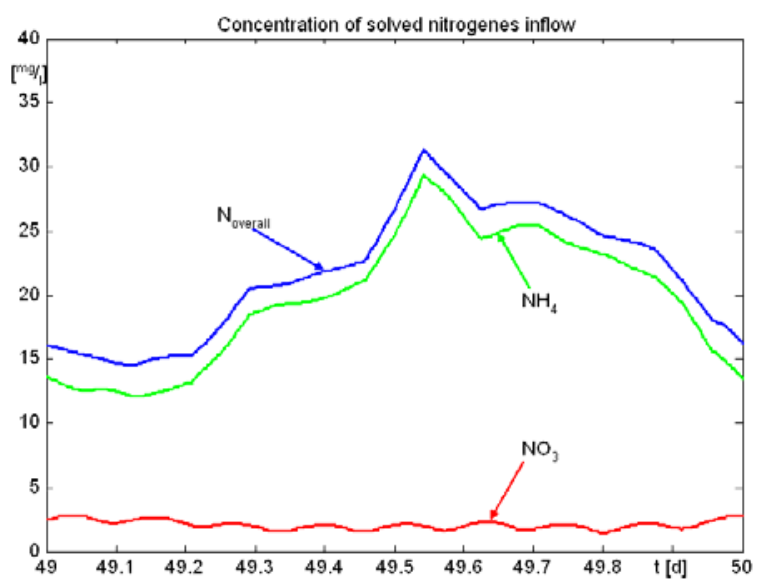

Fig. 12. Influent concentrations with a conventional on-off controller for 1 day

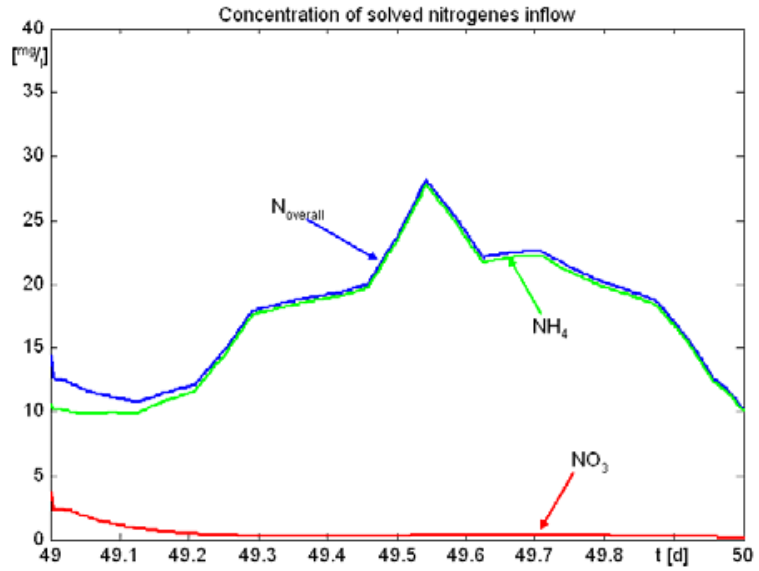

Fig. 13. Influent concentrations with the optimized manipulated variable sequence for 1 day
It can be seen that the effluent concentrations are below the given legal limits with both the conventional and with the predictive on-off controller. Correspondingly the costs which can occur were prevented in both cases. But it can also be seen that the optimized manipulated variable sequence produces effluent concentrations which are significantly higher than the concentrations with the traditional on-off controller.

Figs. 14 and 15 show the reference and controlled signals of the oxygen concentration and the aeration rate for the conventional on-off controller for 1 and 0.2 day's, respectively.

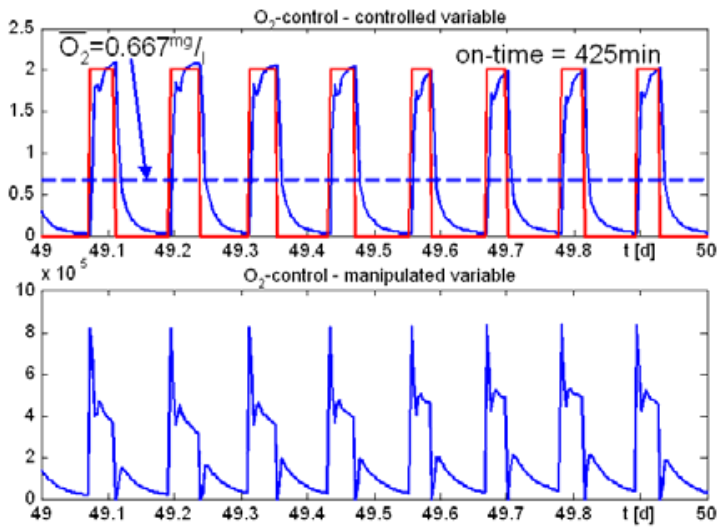

Fig. 14. Aeration control with a conventional on-off controller for 1 day

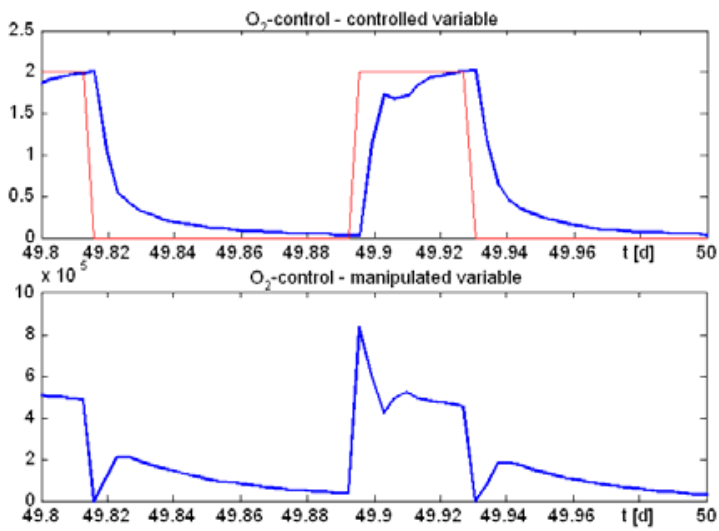

Fig. 15. Aeration control with a conventional on-off controller zoomed for 0.2 day's

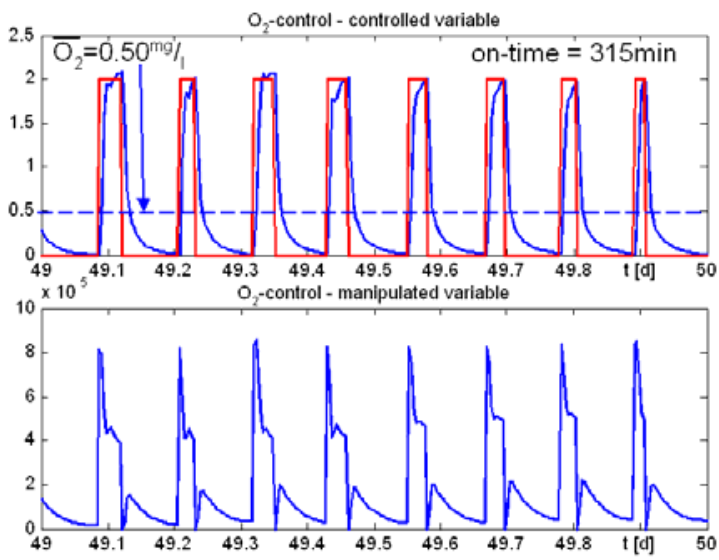

Fig. 16. Aeration control with the optimized manipulated variable sequence for 1 day 


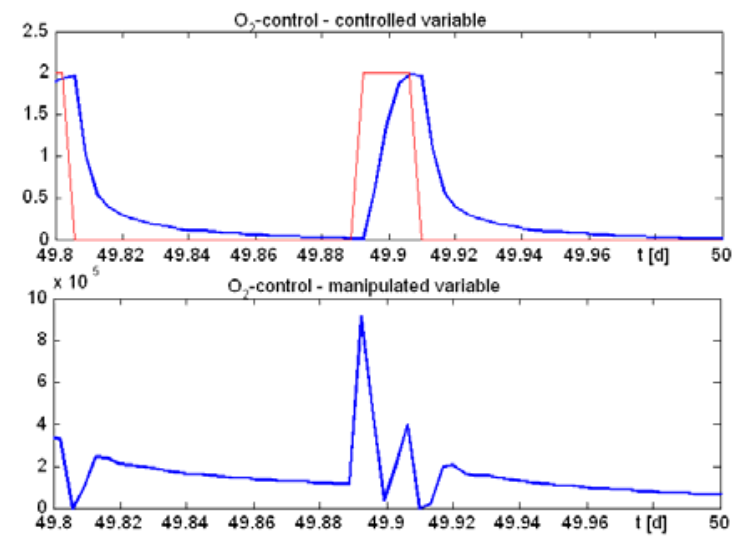

Fig. 17. Aeration control with the optimized manipulated variable sequence zoomed for 0.2 day's

Figs. 16 and 17 show the same signals for the optimized manipulated variable sequence for 1 and 0.2 day's, respectively.

As it is seen in Figures 14 and 16 the mean value of the oxygen concentration reference signal in the biological reactor was reduced from $0.667 \mathrm{mg} / \mathrm{l}$ to $0.5 \mathrm{mg} / \mathrm{l}$ due to the predictive control.

The absolute number of switches did not decrease and was 16 in both cases but the duration of the aeration was significantly reduced from $425 \mathrm{~min}$ to $315 \mathrm{~min}$, thus about by $35 \%$. The aeration duration is proportional to the costs that really occur because of the aeration. As mentioned earlier, the task was to minimize these costs, as well.

\section{CONCLUSION}

It was shown, that a predictive on-off cost minimizing control is able to minimize the necessary costs of the aeration without violating the effluent concentration limit values given by the laws of the Ministry for Environment. Instead of a quadratic function the real costs of the operation were minimized. As a consequence the minimization could not be solved analytically and the optimal manipulated sequence (the duration of the aeration) was calculated iteratively by using a genetic algorithm.

In the case investigated the optimization resulted in slightly worse effluent concentrations than with conventional on-off control, but anyhow all concentrations were kept in their limits. On the other hand the optimization resulted in a significantly lower air inflow, which means that the costs of the aeration were relevantly reduced.

The evaluated cost function defines a summarization of the significant costs of an intermittently operated waste water treatment plant and is therefore a good basis for optimizations of municipal plants (of course there might be an adaptation necessary for the explicit cases).

\section{ACKNOWLEDGMENTS}

This project was supported by the Federal Ministry for Education and Research (BMBF) as promotion of Applied Research and Development, recommended by the German Federation of Industrial Cooperative Research Associations "Otto von Guericke". The authors thank also Dr. J. Alex from IFAK (Magdeburg, FRG) for his consultation on the modelling of the waste water treatment technology. The authors are thankful to Dr. I. Sekaj (Department of Automatic Control Systems, Faculty of Electrical Engineering and Information Technology, Slovak University of Technology, Slovak Republic) for his help in applying the genetic algorithm for the case presented. The cooperation in the subject of predictive control with the Budapest University of Technology and Economics is supported by the University of Applied Science Cologne and by the program of EU-Socrates.

\section{REFERENCES}

Alex, J.; To, T.B.; Hartwig, P.: Improved Design and Optimization of Aeration Control for WWTPs by Dynamic Simulation (2002). Water Science \& Technology, 45, No. 4-5, 365-372.

Fikar, M., B. Chachuat, M.A. Latifi (2002). Optimal Control Design for an Alternating Activated Sludge Process. Proc. 5th Scientific-Technical Conf. Process Control 2002. Kouty nad Desnou, Czech Republic

Henze, M., C.P.L. Grady, W. Gujer, G.v.R. Marais, T. Matsuo (1987). Activated Sludge Model No. 1. Technical Report 1, IAWQ, London, UK

Jumar, U.; Alex, J. (2002). Simulation-based Design of Aeration Control for Wastewater Treatment Plants. AUT 2002 - 2nd International Conference on Automatic Control; Santiago de Cuba.

Kim, H., T.J. McAvoy, J.S. Anderson, O.J. Hao (2000). Control of an alternating aerobic-anoxic activated sludge system - Part 2: optimization using linearized model. Control Engineering Practice 8, pp. 279-289

Latifi, M.A. (2003). Theoretical and Practical Aspects of Dynamic Optimization of Chemical Processes. 14th Int. Conference Process Control 2003, Strebske Pleso, Slovakia, pp. 205-1-205-11

Lukasse, L.J.S, K.J. Keesman, G.v. Straten (1999). A recursively identified model for short-term predicitions of NH4/NO3-concentrations in alternating activated sludge processes. Journal of Process Control 9, pp. 87-100

Sekaj, I. (2002). Genetic Algorithms with Changing Criterion Functions, Intelligent Technologies Theory and Applications, P. Sincak et al. (Eds), IOS Press, 2002, ISBN 158603256 9, pp. 183188 